Vietnam Journal of Mechanics, VAST, Vol. 29, No. 3 (2007), pp. $257-269$

Special Issue Dedicated to the Memory of Prof. Nguyen Van Dao

\title{
NON-LINEAR DYNAMICAL ANALYSIS OF LAMINATED REINFORCED COMPOSITE DOUBLY CURVED SHALLOW SHELLS
}

\author{
DaO Huy Bich and Vu Do Long \\ Vietnam National University, Hanoi
}

\begin{abstract}
The present paper deals with a non-linear dynamical analysis of laminated reinforced composite doubly curved shallow shells. The motion equations of shell based upon the thin shell theory considering the geometrical non- linearity and the Lekhnitsky's smeared stiffeners technique. Simultaneous ordinary differential equations are obtained by means of Bubnov-Galerkin's procedure. Non-linear responses are calculated by using an iterative procedure in conjunction with Newmark constant acceleration scheme. Obtained results allow to discover the influence of stiffeners, the shell geometry on the non-linear response of eccentrically stiffened laminated composite shells.
\end{abstract}

\section{INTRODUCTION}

Reinforced laminated structures like plates and shallow shells are widely used in different types of structures such as aircraft and hull of ships. The stiffening member provides the benefit of added load-carrying capability with a relatively small additional weight penalty. The static and dynamic problems of laminated plates with geometrical nonlinearity were described in a book by Chia [1] extensively. Sathyamoorthy [2] reviewed a great number of papers dealing with the non-linear vibration of plates. Unreinforced composite cylindrical shells have been analysed by analytical solution procedure or finite element technique [3-9]. Static and buckling analyses of reinforced cylindrical shells have been investigated in [10-14]. However the non-linear analysis of laminated reinforced composite shells in general has received comparatively little attenion, this may be because of their inherent complexity, when the loading is large the geometric non-linearity of the shell must be considered. Approximated analytical solutions to the large deflection theory of unreinforced laminated composite doubly curved shallow shells were considered in [15-17].

The purpose of the present paper is to investigate the non-linear dynamical problem of laminated reinforced composite doubly curved shallow shells. The motion equations of reinforced composite shells in terms of displacement are developed based upon the thin shell theory considering geometric non- linearity and the Lekhnitsky's smeared stiffeners technique. Simultaneous ordinary differential equations are obtained by means of BubnovGalerkin's procedure. Non-linear responses are calculated by using an iterative procedure in conjunction with Newmark constant acceleration scheme. The influence of stiffeners, the shell geometry on the non-linear responses of eccentrically stiffened laminated composite shell are considered. 


\section{GOVERNING EQUATIONS}

Consider a symmetrically laminated composite doubly curved shallow shells of thickness $h$ and in- plane edges $a$ and $b$. The shell is reinforced by eccentrically longitudinal and transversal composite stiffeners and subjected to the transverse load of intensity $q\left(x_{1}, x_{2}, t\right)$.

The stiffeners may be also sleeves with SMA wire and the sleeves bonded on the shell surface. The wire is not bonded to the sleeves, so it may slide freely along the stiffener. However the wire is embedded within the sleeves, so that it participates in bending of the stiffeners and the shell.

The non-linear strain-displacement relationships based upon the thin shell theory. The stress resultants and couples of reinforced composite shells are obtained by using the constitutive stress-strain equations for the shell composite material and the Lekhnitsky's smeared stiffeners technique considered as followings

$$
\begin{aligned}
N_{1}= & \left(A_{11}+\frac{E A_{1}}{s_{1}}\right)\left[\frac{\partial u}{\partial x_{1}}-k_{1} w+\frac{1}{2}\left(\frac{\partial w}{\partial x_{1}}\right)^{2}\right]+A_{12}\left[\frac{\partial v}{\partial x_{2}}-k_{2} w+\frac{1}{2}\left(\frac{\partial w}{\partial x_{2}}\right)^{2}\right] \\
& -\frac{E A_{1}}{s_{1}} z_{1} \frac{\partial^{2} w}{\partial x_{1}^{2}}+\frac{N^{r}}{s_{1}}, \\
N_{2}= & A_{12}\left[\frac{\partial u}{\partial x_{1}}-k_{1} w+\frac{1}{2}\left(\frac{\partial w}{\partial x_{1}}\right)^{2}\right]+\left(A_{22}+\frac{E A_{2}}{s_{2}}\right)\left[\frac{\partial v}{\partial x_{2}}-k_{2} w+\frac{1}{2}\left(\frac{\partial w}{\partial x_{2}}\right)^{2}\right] \\
& -\frac{E A_{2}}{s_{2}} z_{2} \frac{\partial^{2} w}{\partial x_{2}^{2}}+\frac{N^{r}}{s_{2}}, \\
N_{6}= & A_{66}\left(\frac{\partial u}{\partial x_{2}}+\frac{\partial v}{\partial x_{1}}+\frac{\partial w}{\partial x_{1}} \frac{\partial w}{\partial x_{2}}\right),
\end{aligned}
$$

and

$$
\begin{aligned}
& M_{1}=-\left(D_{11}+\frac{E I_{1}}{s_{1}}\right) \frac{\partial^{2} w}{\partial x_{1}^{2}}-D_{12} \frac{\partial^{2} w}{\partial x_{2}^{2}}+\frac{E A_{1} z_{1}}{s_{1}}\left[\frac{\partial u}{\partial x_{1}}-k_{1} w+\frac{1}{2}\left(\frac{\partial w}{\partial x_{1}}\right)^{2}\right], \\
& M_{2}=-D_{12} \frac{\partial^{2} w}{\partial x_{1}^{2}}-\left(D_{22}+\frac{E I_{2}}{s_{2}}\right) \frac{\partial^{2} w}{\partial x_{2}^{2}}+\frac{E A_{2} z_{2}}{s_{2}}\left[\frac{\partial v}{\partial x_{2}}-k_{2} w+\frac{1}{2}\left(\frac{\partial w}{\partial x_{2}}\right)^{2}\right], \\
& M_{6}=-2 D_{66} \frac{\partial^{2} w}{\partial x_{1} \partial x_{2}},
\end{aligned}
$$

where

$$
\left(A_{i j}, D_{i j}\right)=\sum_{k=1}^{n_{1}} \int_{h_{k-1}}^{h_{k}}\left(\bar{Q}_{i j}\right)^{(k)}\left(1, z^{2}\right) d z,(i, j=1,2,6)
$$

are extensional and bending stiffnesses of the shell without stiffeners, $n_{1}$ is the number of composite layers of the shell, $\bar{Q}_{i j}^{(k)}$ are the transformed stiffnesses of $\mathrm{k}^{\text {th }}$ layer. Note that in a multilayered symmetrically laminated material the coupling stiffnesses $B_{i j}$ are equal to zero and the extensional $A_{16}, A_{26}$ and bending $D_{16}, D_{26}$ stiffnesses are negligible compared to the other stiffnesses.

$E$ - denotes the effective modulus in the axial direction of the corresponding stiffener;

$u, v$ and $w$ are displacements of the middle surface points along $x_{1}, x_{2}$ and $x_{3} \equiv z$ directions respectively ; 
$k_{1}=\frac{1}{R_{1}}, k_{2}=\frac{1}{R_{2}}$ are principal curvatures of the shell, and $R_{1}, R_{2}$ - radii of curvatures; $A_{1}, A_{2}$ - cross section areas of the stiffeners;

$I_{1}, I_{2}$ - inertia moments of stiffener cross sections ;

$z_{1}, z_{2}$ - eccentricities of the stiffener with respect to the middle surface of the shell; the torsional stiffness of the stiffener is disregarded;

$s_{1}, s_{2}$ - spacings of the longitudinal and transversal stiffeners respectively.

$N^{r}$ denotes the recovery tensile force in SMA wire, this force does not generate a bending moment, because the wire can move freely along the sleeves.

The motion equations of a laminated doubly curved shallow shell are

$$
\begin{gathered}
\frac{\partial N_{1}}{\partial x_{1}}+\frac{\partial N_{6}}{\partial x_{2}}=J_{0} \frac{\partial^{2} u}{\partial t^{2}}-J_{1} \frac{\partial^{3} w}{\partial x_{1} \partial t^{2}}, \\
\frac{\partial N_{6}}{\partial x_{1}}+\frac{\partial N_{2}}{\partial x_{2}}=J_{0} \frac{\partial^{2} v}{\partial t^{2}}-J_{1} \frac{\partial^{3} w}{\partial x_{2} \partial t^{2}}, \\
\frac{\partial^{2} M_{1}}{\partial x_{1}^{2}}+2 \frac{\partial^{2} M_{6}}{\partial x_{1} \partial x_{2}}+\frac{\partial^{2} M_{2}}{\partial x_{2}^{2}}+k_{1} N_{1}+k_{2} N_{2}+ \\
\frac{\partial}{\partial x_{1}}\left(N_{1} \frac{\partial w}{\partial x_{1}}+N_{6} \frac{\partial w}{\partial x_{2}}\right)+\frac{\partial}{\partial x_{2}}\left(N_{6} \frac{\partial w}{\partial x_{1}}+N_{2} \frac{\partial w}{\partial x_{2}}\right)+q= \\
J_{0} \frac{\partial^{2} w}{\partial t^{2}}+J_{1}\left(\frac{\partial^{3} u}{\partial x_{1} \partial t^{2}}+\frac{\partial^{3} v}{\partial x_{2} \partial t^{2}}\right)-J_{2}\left(\frac{\partial^{4} w}{\partial x_{1}^{2} \partial t^{2}}+\frac{\partial^{4} w}{\partial x_{2}^{2} \partial t^{2}}\right),
\end{gathered}
$$

where

$$
\begin{gathered}
J_{i}=\sum_{k=1}^{n_{1}} \int_{h_{k-1}}^{h_{k}} \rho^{(k)} z^{i} d z+\left(\sum_{k=1}^{n_{2}} \int_{h_{k-1}}^{h_{k}} \rho^{(k)} z^{i} d z\right) \frac{d_{1}}{s_{1}}+\left(\sum_{k=1}^{n_{3}} \int_{h_{k-1}}^{h_{k}} \rho^{(k)} z^{i} d z\right) \frac{d_{2}}{s_{2}} \\
(i=0,1,2)
\end{gathered}
$$

$n_{2}, n_{3}$ are the number of composite layers and $d_{1}, d_{2}$ are the widths of cross sections of the longitudinal and transversal composite stiffeners respectively; $\rho^{(k)}$ is the mass density of $k^{\text {th }}$ composite layer.

The substitution of equations (2.1) and (2.2) into the motion equations (2.3) yields the system of motion equations in terms of displacements

$$
\begin{aligned}
& L_{11}(u)+L_{12}(v)+L_{13}(w)+P_{1}(w)=J_{0} \frac{\partial^{2} u}{\partial t^{2}}-J_{1} \frac{\partial^{3} w}{\partial x_{1} \partial t^{2}}, \\
& L_{21}(u)+L_{22}(v)+L_{23}(w)+P_{2}(w)=J_{0} \frac{\partial^{2} v}{\partial t^{2}}-J_{1} \frac{\partial^{3} w}{\partial x_{2} \partial t^{2}}, \\
& L_{31}(u)+L_{32}(v)+L_{33}(w)+P_{3}(w)+Q_{3}(u, w)+R_{3}(v, w)= \\
& =q+N^{r}\left(\frac{k_{1}}{s_{1}}+\frac{k_{2}}{s_{2}}\right)-J_{0} \frac{\partial^{2} w}{\partial t^{2}}-J_{1}\left(\frac{\partial^{3} u}{\partial x_{1} \partial t^{2}}+\frac{\partial^{3} v}{\partial x_{2} \partial t^{2}}\right) \\
& +J_{2}\left(\frac{\partial^{4} w}{\partial x_{1}^{2} \partial t^{2}}+\frac{\partial^{4} w}{\partial x_{2}^{2} \partial t^{2}}\right),
\end{aligned}
$$


where $L_{i j}$ are linear operators of the form

$$
\begin{aligned}
L_{11}= & \left(A_{11}+\frac{E A_{1}}{s_{1}}\right) \frac{\partial^{2}}{\partial x_{1}^{2}}+A_{66} \frac{\partial^{2}}{\partial x_{2}^{2}}, \\
L_{12}= & L_{21}=\left(A_{12}+A_{66}\right) \frac{\partial^{2}}{\partial x_{1} \partial x_{2}}, \\
L_{13}= & L_{31}=-\left[\left(A_{11}+\frac{E A_{1}}{s_{1}}\right) k_{1}+A_{12} k_{2}\right] \frac{\partial}{\partial x_{1}}-\frac{E A_{1} z_{1}}{s_{1}} \frac{\partial^{3}}{\partial x_{1}^{3}}, \\
L_{22}= & A_{66} \frac{\partial^{2}}{\partial x_{1}^{2}}+\left(A_{22}+\frac{E A_{2}}{s_{2}}\right) \frac{\partial^{2}}{\partial x_{2}^{2}}, \\
L_{23}= & L_{32}=-\left[\left(A_{22}+\frac{E A_{2}}{s_{2}}\right) k_{2}+A_{12} k_{1}\right] \frac{\partial}{\partial x_{2}}-\frac{E A_{2} z_{2}}{s_{2}} \frac{\partial^{3}}{\partial x_{2}^{3}}, \\
L_{33}= & \left(D_{11}+\frac{E I_{1}}{s_{1}}\right) \frac{\partial^{4}}{\partial x_{1}^{4}}+2\left(D_{12}+2 D_{66}\right) \frac{\partial^{4}}{\partial x_{1}^{2} \partial x_{2}^{2}}+\left(D_{22}+\frac{E I_{2}}{s_{2}}\right) \frac{\partial^{4}}{\partial x_{2}^{4}}+ \\
& +\left(2 \frac{E A_{1} z_{1}}{s_{1}} k_{1}-\frac{N^{r}}{s_{1}}\right) \frac{\partial^{2}}{\partial x_{1}^{2}}+\left(2 \frac{E A_{2} z_{2}}{s_{2}} k_{2}-\frac{N^{r}}{s_{2}}\right) \frac{\partial^{2}}{\partial x_{2}^{2}}+ \\
& +k_{1}^{2}\left(A_{11}+\frac{E A_{1}}{s_{1}}\right)+2 k_{1} k_{2} A_{12}+k_{2}^{2}\left(A_{22}+\frac{E A_{2}}{s_{2}}\right)
\end{aligned}
$$

and non-linear functions $P_{i}(w),(i=1,2,3), Q_{3}(u, w), R_{3}(v, w)$ are represented as

$$
\begin{aligned}
& P_{1}(w)=\left(A_{11}+\frac{E A_{1}}{s_{1}}\right) \frac{\partial w}{\partial x_{1}} \frac{\partial^{2} w}{\partial x_{1}^{2}}+\left(A_{12}+A_{66}\right) \frac{\partial w}{\partial x_{2}} \frac{\partial^{2} w}{\partial x_{1} \partial x_{2}}+A_{66} \frac{\partial w}{\partial x_{1}} \frac{\partial^{2} w}{\partial x_{2}^{2}}, \\
& P_{2}(w)=\left(A_{22}+\frac{E A_{2}}{s_{2}}\right) \frac{\partial w}{\partial x_{2}} \frac{\partial^{2} w}{\partial x_{2}^{2}}+\left(A_{12}+A_{66}\right) \frac{\partial w}{\partial x_{1}} \frac{\partial^{2} w}{\partial x_{1} \partial x_{2}}+A_{66} \frac{\partial w}{\partial x_{2}} \frac{\partial^{2} w}{\partial x_{1}^{2}} \\
& P_{3}(w)=\left[\left(A_{11}+\frac{E A_{1}}{s_{1}}\right) k_{1}+A_{12} k_{2}\right]\left[\frac{1}{2}\left(\frac{\partial w}{\partial x_{1}}\right)^{2}+w \frac{\partial^{2} w}{\partial x_{1}^{2}}\right]+ \\
& +\left[\left(A_{22}+\frac{E A_{2}}{s_{2}}\right) k_{2}+A_{12} k_{1}\right]\left[\frac{1}{2}\left(\frac{\partial w}{\partial x_{2}}\right)^{2}+w \frac{\partial^{2} w}{\partial x_{2}^{2}}\right]- \\
& -\frac{3}{2}\left(A_{11}+\frac{E A_{1}}{s_{1}}\right)\left(\frac{\partial w}{\partial x_{1}}\right)^{2} \frac{\partial^{2} w}{\partial x_{1}^{2}}-\frac{3}{2}\left(A_{22}+\frac{E A_{2}}{s_{2}}\right)\left(\frac{\partial w}{\partial x_{2}}\right)^{2} \cdot \frac{\partial^{2} w}{\partial x_{2}^{2}}- \\
& -\frac{1}{2}\left(A_{12}+2 A_{66}\right) \frac{\partial^{2} w}{\partial x_{1}^{2}}\left(\frac{\partial w}{\partial x_{2}}\right)^{2}-\frac{1}{2}\left(A_{12}+2 A_{66}\right) \frac{\partial^{2} w}{\partial x_{2}^{2}}\left(\frac{\partial w}{\partial x_{1}}\right)^{2}- \\
& -2\left(A_{12}+2 A_{66}\right) \frac{\partial w}{\partial x_{1}} \frac{\partial w}{\partial x_{2}} \frac{\partial^{2} w}{\partial x_{1} \partial x_{2}}, \\
& Q_{3}(u, w)=-\left(A_{11}+\frac{E A_{1}}{s_{1}}\right)\left(\frac{\partial^{2} u}{\partial x_{1}^{2}} \frac{\partial w}{\partial x_{1}}+\frac{\partial u}{\partial x_{1}} \frac{\partial^{2} w}{\partial x_{1}^{2}}\right)-\left(A_{12}+A_{66}\right) \frac{\partial^{2} u}{\partial x_{1} \partial x_{2}} \frac{\partial w}{\partial x_{2}} \\
& -A_{66} \frac{\partial^{2} u}{\partial x_{2}^{2}} \frac{\partial w}{\partial x_{1}}-A_{12} \frac{\partial u}{\partial x_{1}} \frac{\partial^{2} w}{\partial x_{2}^{2}}-2 A_{66} \frac{\partial u}{\partial x_{2}} \frac{\partial^{2} w}{\partial x_{1} \partial x_{2}},
\end{aligned}
$$




$$
\begin{aligned}
R_{3}(v, w)= & -\left(A_{22}+\frac{E A_{2}}{s_{2}}\right)\left(\frac{\partial^{2} v}{\partial x_{2}^{2}} \frac{\partial w}{\partial x_{2}}+\frac{\partial v}{\partial x_{2}} \frac{\partial^{2} w}{\partial x_{2}^{2}}\right)-\left(A_{12}+A_{66}\right) \frac{\partial^{2} v}{\partial x_{1} \partial x_{2}} \frac{\partial w}{\partial x_{1}} \\
& -A_{66} \frac{\partial^{2} v}{\partial x_{1}^{2}} \frac{\partial w}{\partial x_{2}}-A_{12} \frac{\partial v}{\partial x_{2}} \frac{\partial^{2} w}{\partial x_{1}^{2}}-2 A_{66} \frac{\partial v}{\partial x_{1}} \frac{\partial^{2} w}{\partial x_{1} \partial x_{2}}
\end{aligned}
$$

Note that with $k_{1}=0$ the system of equations (2.4), (2.5) and (2.6) becomes a system of motion equations of a reinforced composite cylindrical panel and with $k_{1}=k_{2}=0$ we recieve a system of motion equations for a reinforced composite plate.

A. combination of boundary conditions may be assumed to exist at the edges of the shell. Morever for dynamical analysis it is necessary to give initial conditions.

\section{LINEAR VIBRATION OF A REINFORCED COMPOSITE DOUBLY CURVED SHALLOW SHELL}

Omitting non-linear terms and no considering effect of SMA in the motion equations (2.4) yields the equations system of linear vibration of a reinforced composite shallow shell

$$
\begin{aligned}
L_{11}(u)+L_{12}(v)+L_{13}(w)= & J_{0} \frac{\partial^{2} u}{\partial t^{2}}-J_{1} \frac{\partial^{3} w}{\partial x_{1} \partial t^{2}}, \\
L_{21}(u)+L_{22}(v)+L_{23}(w)= & J_{0} \frac{\partial^{2} v}{\partial t^{2}}-J_{1} \frac{\partial^{3} w}{\partial x_{2} \partial t^{2}}, \\
L_{31}(u)+L_{32}(v)+L_{33}(w)= & q-J_{0} \frac{\partial^{2} w}{\partial t^{2}}-J_{1}\left(\frac{\partial^{3} u}{\partial x_{1} \partial t^{2}}+\frac{\partial^{3} v}{\partial x_{2} \partial t^{2}}\right) \\
& +J_{2}\left(\frac{\partial^{4} w}{\partial x_{1}^{2} \partial t^{2}}+\frac{\partial^{4} w}{\partial x_{2}^{2} \partial t^{2}}\right)
\end{aligned}
$$

where linear operators $L_{i j}$ are taken by (2.5).

First of all consider the natural vibration of the shell, i.e with $q=0$. The shallow shell considered in the following analysis is simply supported and displacements of its end cross sections are not restrained. The boundary conditions can be satisfied if we take the mode shape as follows

$$
\begin{aligned}
u\left(x_{1}, x_{2}, t\right) & =\sum_{m} \sum_{n} U_{m n}(t) \cos \frac{m \pi x_{1}}{a} \sin \frac{n \pi x_{2}}{b}, \\
v\left(x_{1}, x_{2}, t\right) & =\sum_{m} \sum_{n} V_{m n}(t) \sin \frac{m \pi x_{1}}{a} \cos \frac{n \pi x_{2}}{b}, \\
w\left(x_{1}, x_{2}, t\right) & =\sum_{m} \sum_{n} W_{m n}(t) \sin \frac{m \pi x_{1}}{a} \sin \frac{n \pi x_{2}}{b},
\end{aligned}
$$

where $m, n$ are natural numbers representing the number of halfwaves in the $x_{1}$ and $x_{2}$ directions respectively.

Substituting expressions (3.2) into the motion equations (3.1) yields the set of three linear second order ordinary differential equations in term of $U_{m n}(t), V_{m n}(t)$ and $W_{m n}(t)$ 


$$
\begin{aligned}
& a_{11} U_{m n}+a_{12} V_{m n}+a_{13} W_{m n}=-J_{0} \ddot{U}_{m n}+J_{1} \frac{m \pi}{a} \ddot{W}_{m n}, \\
& a_{21} U_{m n}+a_{22} V_{m n}+a_{23} W_{m n}=-J_{0} \ddot{V}_{m n}+J_{1} \frac{n \pi}{b} \ddot{W}_{m n}, \\
& a_{31} U_{m n}+a_{32} V_{m n}+a_{33} W_{m n}=-J_{0} \ddot{W}_{m n}+J_{1} \frac{m \pi}{a} \ddot{U}_{m n} \\
& +J_{1} \frac{n \pi}{b} \ddot{V}_{m n}-J_{2}\left[\left(\frac{m \pi}{a}\right)^{2}+\left(\frac{n \pi}{b}\right)^{2}\right] \ddot{W}_{m n},
\end{aligned}
$$

that can be rewritten in matrix form

$$
[M]\{\ddot{f}\}+[K]\{f\}=0
$$

where denote

$$
\begin{gathered}
{[M]=\left[\begin{array}{ccc}
J_{0} & 0 & -J_{1}(m \pi) / a \\
0 & J_{0} & -J_{1}(n \pi) / b \\
-J_{1} \frac{m \pi}{a} & -J_{1} \frac{n \pi}{b} & J_{0}+J_{2}\left[\left(\frac{m \pi}{a}\right)^{2}+\left(\frac{n \pi}{b}\right)^{2}\right]
\end{array}\right]} \\
{[K]=\left[\begin{array}{lll}
a_{11} & a_{12} & a_{13} \\
a_{21} & a_{22} & a_{23} \\
a_{31} & a_{32} & a_{33}
\end{array}\right]} \\
\{f\}=\left[f_{1}(t) f_{2}(t) f_{3}(t)\right]^{T} \equiv\left[U_{m n}(t) V_{m n}(t) W_{m n}(t)\right]^{T},
\end{gathered}
$$

the dot $\operatorname{sign}($.$) denotes a derivative with respect to time, [...] denotes a matrix and \{$. denotes a column vector. The coefficients $a_{i j}$ in (3.3) are determined as follows

$$
\begin{aligned}
a_{11}= & \left(A_{11}+\frac{E A_{1}}{s_{1}}\right)\left(\frac{m \pi}{a}\right)^{2}+A_{66}\left(\frac{n \pi}{b}\right)^{2}, \\
a_{12}= & a_{21}=\left(A_{12}+A_{66}\right) \frac{\pi^{2} m n}{a b}, \\
a_{13}= & a_{31}=\left[\left(A_{11}+\frac{E A_{1}}{s_{1}}\right) k_{1}+A_{12} k_{2}\right] \frac{m \pi}{a}-\frac{E A_{1} z_{1}}{s_{1}}\left(\frac{m \pi}{a}\right)^{3}, \\
a_{22}= & \left(A_{22}+\frac{E A_{2}}{s_{2}}\right)\left(\frac{n \pi}{b}\right)^{2}+A_{66}\left(\frac{m \pi}{a}\right)^{2}, \\
a_{23}= & a_{32}=\left[\left(A_{22}+\frac{E A_{2}}{s_{2}}\right) k_{2}+A_{12} k_{1}\right] \frac{n \pi}{b}-\frac{E A_{2} z_{2}}{s_{2}}\left(\frac{n \pi}{b}\right)^{3}, \\
a_{33}= & \left(D_{11}+\frac{E I_{1}}{s_{1}}\right)\left(\frac{m \pi}{a}\right)^{4}+2\left(D_{12}+2 D_{66}\right)\left(\frac{m \pi}{a}\right)^{2}\left(\frac{n \pi}{b}\right)^{2}+ \\
& +\left(D_{22}+\frac{E I_{2}}{s_{2}}\right)\left(\frac{n \pi}{b}\right)^{4}-2 \frac{E A_{1} z_{1}}{s_{1}} k_{1}\left(\frac{m \pi}{a}\right)^{2}-2 \frac{E A_{2} z_{2}}{s_{2}} k_{2}\left(\frac{n \pi}{b}\right)^{2} \\
& +\left(A_{11}+\frac{E A_{1}}{s_{1}}\right) k_{1}^{2}+\left(A_{22}+\frac{E A_{2}}{s_{2}}\right) k_{2}^{2}+2 k_{1} k_{2} A_{12} .
\end{aligned}
$$

Putting $\{f(t)\}=\cdot\left\{f_{0}\right\} e^{i \omega t}$ into equation (2.4) reduces to

$$
\left([K]-\omega^{2}[M]\right)\left\{f_{0}\right\}=0 .
$$


Because the components of $\left\{f_{0}\right\}$ do not vanish simultaneously then the determinant of coefficients in the equation (3.7) must be equal to zero

$$
\begin{aligned}
& \operatorname{Det}\left|[K]-\omega^{2}[M]\right|= \\
& \left|\begin{array}{ccc}
a_{11}-J_{0} \omega^{2} & a_{12} & a_{13}+J_{1} \frac{m \pi}{a} \omega^{2} \\
a_{21} & a_{22}-J_{0} \omega^{2} & a_{23}+J_{1} \frac{n \pi}{b} \omega^{2} \\
a_{31}+J_{1}\left(\frac{m \pi}{a}\right) \omega^{2} & a_{32}+J_{1}\left(\frac{n \pi}{b}\right) \omega^{2} & a_{33}-\left[J_{0}+J_{2}\left(\left(\frac{m \pi}{a}\right)^{2}+\left(\frac{n \pi}{b}\right)^{2}\right)\right] \omega^{2}
\end{array}\right|=0
\end{aligned}
$$

This is an algebraic equation of 3-degree with respect to $\omega^{2}$ for determining fundamental frequencies of the natural vibration of the shell.

Now consider the forced vibration of reinforced composite doubly curved shell subjected to excited distributed transverse load of intensity $q\left(x_{1}, x_{2}, t\right)$. We represent function $q\left(x_{1}, x_{2}, t\right)$ in the Fourier series

$$
q\left(x_{1}, x_{2}, t\right)=\sum_{m} \sum_{n} q_{m n}(t) \sin \frac{m \pi x_{1}}{a} \sin \frac{n \pi x_{2}}{b},
$$

where

$$
q_{m n}(t)=\frac{4}{a b} \int_{0}^{a} \int_{0}^{b} q\left(x_{1}, x_{2}, t\right) \sin \frac{m \pi x_{1}}{a} \sin \frac{n \pi x_{2}}{b} d x_{1} d x_{2}
$$

then the equation of forced vibration of the shell is

$$
[M]\{\ddot{f}\}+[K]\{f\}=\{F\},
$$

where $[M],[K]$ are the same as in (3.4), while $\{F\}$ is taken by

$$
\{F\}=\left(\begin{array}{lll}
0 & 0 & q_{m n}(t)
\end{array}\right)^{T} .
$$

Suppose the external force $\{F\}=\left\{F_{0}\right\} \sin \Omega t$, i.e $\left\{F_{0}=\left(0,0, q_{m n}^{0}\right)^{T}\right.$, we scek a solution to the equation (3.9) in the form $\{f\}=\left\{f_{0}^{*}\right\} \sin \Omega t$, where $\left\{f_{0}^{*}\right\}$ is an amplitude of the forced vibration of the shell being defined by

$$
\left([K]-\Omega^{2}[M]\right) \cdot\left\{f_{0}^{*}\right\}=\left\{F_{0}\right\} .
$$

We can see that if $\Omega=\omega$, i.e the frequency of external force coincides with a natural frequency of the shell, where $\omega$ satisfies the equation $(3.8)$, then $\operatorname{Det}\left|[K]-\Omega^{2}[M]\right|=0$ so that the matrix $[K]-\Omega^{2}[M]$ becomes singular, it leads to the amplitude of the forced vibration $\left\{f_{0}^{*}\right\}$ to be undefined, that corresponds to the resonance phenomenon. If $\Omega \neq \omega$, $\operatorname{Det}\left|[K]-\Omega^{2}[M]\right| \neq 0$ then the amplitude $\left\{f_{0}^{*}\right\}$ is determined by

$$
\left\{f_{0}^{*}\right\}=\left([K]-\Omega^{2}[M]\right)^{-1}\left\{F_{0}\right\}
$$




\section{NON-LINEAR VIBRATION OF REINFORCED COMPOSITE DOUBLY CURVED SHALLOW SHELLS}

Because of complexity an approximation is accepted in the representation of the shell displacements by a single term of a double Fourier series

$$
\begin{aligned}
u & =U_{m n}(t) \cos \frac{m \pi x_{1}}{a} \sin \frac{n \pi x_{2}}{b}, \\
v & =V_{m n}(t) \sin \frac{m \pi x_{1}}{a} \cos \frac{n \pi x_{2}}{b}, \\
w & =W_{m n}(t) \sin \frac{m \pi x_{1}}{a} \sin \frac{n \pi x_{2}}{b},
\end{aligned}
$$

where $m, n$ may be taken arbitrarily.

Substituting expressions (4.1) into the motion equations (2.4) and applying the Bubnov-Galerkin procedure we obtain a set of equations

$$
\begin{aligned}
& a_{11} U_{m n}+a_{12} V_{m n}+a_{13} W_{m n}-c_{1} W_{m n}^{2}+J_{0} \ddot{U}_{m n}-J_{1} \frac{m \pi}{a} \ddot{I}_{m n}=0, \\
& a_{12} U_{m n}+a_{22} V_{m n}+a_{23} W_{m n}-c_{2} W_{m n}^{2}+J_{0} \ddot{V}_{m n}-J_{1} \frac{n \pi}{b} \ddot{U}_{m n}=0 . \\
& a_{13} U_{m n}+a_{23} V_{m n}+a_{33} W_{m n}-c_{3} W_{m n}^{2}+c_{1} W_{m n}^{3}-c_{5} U_{m n} W_{m n}-c_{6} V_{m n} W_{m n} \\
& -J_{1} \frac{m \pi}{a} \ddot{U}_{m n}-J_{1} \frac{n \pi}{b} \ddot{V}_{m n}+\left[J_{0}+J_{2}\left(\left(\frac{m \pi}{a}\right)^{2}+\left(\frac{n \pi}{b}\right)^{2}\right)\right] \ddot{H}_{m n}=q_{m n}(t),
\end{aligned}
$$

where $a_{i j}(i, j=1,2,3)$ were determined as in (3.6) and

$$
\begin{aligned}
q_{m n}(t) & =\frac{4}{a b} \int_{0}^{a} \int_{0}^{b} q\left(x_{1}, x_{2}, t\right) \sin \frac{m \pi x_{1}}{a} \sin \frac{n \pi x_{2}}{b} d x_{1} d x_{2} \\
c_{1} & =\frac{16}{9 \pi a n}\left[\left(A_{12}-A_{66}\right)\left(\frac{n \pi}{b}\right)^{2}-2\left(A_{11}+\frac{E A_{1}}{s_{1}}\right)\left(\frac{m \pi}{a}\right)^{2}\right], \\
c_{2} & =\frac{16}{9 \pi b m}\left[\left(A_{12}-A_{66}\right)\left(\frac{m \pi}{a}\right)^{2}-2\left(A_{22}+\frac{E A_{2}}{s_{2}}\right)\left(\frac{n \pi}{b}\right)^{2}\right], \\
c_{3} & =\frac{16}{3}\left\{\frac{m}{a^{2} n}\left[\left(A_{11}+\frac{E A_{1}}{s_{1}}\right) k_{1}+A_{12} k_{2}\right]+\frac{n}{b^{2} m}\left[\left(A_{22}+\frac{E A_{2}}{s_{2}}\right) k_{2}+A_{12} k_{1}\right]\right\}, \\
c_{4} & =\frac{9}{32}\left[\left(A_{11}+\frac{E A_{1}}{s_{1}}\right)\left(\frac{m \pi}{a}\right)^{4}+\left(A_{22}+\frac{E A_{2}}{s_{2}}\right)\left(\frac{n \pi}{b}\right)^{4}+\frac{2}{9}\left(A_{12}+2 A_{66}\right)\left(\frac{m \pi}{a}\right)^{2}\left(\frac{n \pi}{b}\right)^{2}\right], \\
c_{5} & =\frac{32}{9 \pi^{2} m n}\left[\left(A_{11}+\frac{E A_{1}}{s_{1}}\right)\left(\frac{m \pi}{a}\right)^{3}+\left(A_{12}-A_{66}\right)\left(\frac{m \pi}{a}\right)\left(\frac{n \pi}{b}\right)^{2}\right], \\
c_{6} & =\frac{32}{9 \pi^{2} m n}\left[\left(A_{22}+\frac{E A_{2}}{s_{2}}\right)\left(\frac{n \pi}{b}\right)^{3}+\left(A_{12}-A_{66}\right)\left(\frac{m \pi}{a}\right)^{2}\left(\frac{n \pi}{b}\right)\right],
\end{aligned}
$$

$m, n$ are taken only by odd natural numbers. 
Equations (4.2) can be rewritten in the matrix form

$$
[M]\{\ddot{f}\}+[K(f)]\{f\}=\{F\},
$$

where $[M],\{f\},\{F\}$ are the same as in (3.5), (3.9), but $[K(f)]$ now is not a constant matrix, it contains non-linear coefficients in addition to the usual linear matrix

$$
[K(f)]=\left[\begin{array}{ccc}
a_{11} & a_{12} & a_{13}-c_{1} f_{3} \\
a_{12} & a_{22} & a_{23}-c_{2} f_{3} \\
a_{13}-c_{5} f_{3} & a_{23}-c_{6} f_{3} & a_{33}-c_{3} f_{3}+c_{4} f_{3}^{2}
\end{array}\right],
$$

To solve equation (4.4) an iterative procedure in conjunction with the Newmark constant acceleration scheme is used. Divide the time process by time point $t_{n+1}=$ $(n+1) \Delta t$ and solve equation (4.4) step-by-step. Using Newmark's method, equation (4.4) can be written as

$$
\left[K^{*}(f)_{n+1}\right]\{f\}_{n+1}=\left\{F^{*}\right\}_{n+1},
$$

where

$$
\begin{gathered}
{\left[K^{*}(f)_{n+1}\right]=\left[K(f)_{n+1}\right]+\frac{4}{\Delta t^{2}}[M],} \\
\left\{F^{*}\right\}_{n+1}=\{F\}_{n+1}+[M]\left(\frac{4}{\Delta t^{2}}\{f\}_{n}+\frac{4}{\Delta t}\{\dot{f}\}_{n}+\{\ddot{f}\}_{n}\right) .
\end{gathered}
$$

Once the solution $\{f\}_{n+1}$ is known at $t_{n+1}=(n+1) \Delta t$, the velocity and acceleration at $t_{n+1}$ can be computed from

$$
\begin{aligned}
& \{\ddot{f}\}_{n+1}=\frac{4}{\Delta t^{2}}\left(\{f\}_{n+1}-\{f\}_{n}\right)-\frac{4}{\Delta t}\{\dot{f}\}_{n}-\{\ddot{f}\}_{n}, \\
& \{\dot{f}\}_{n+1}=\{\dot{f}\}_{n}+\frac{\Delta t}{2}\left(\{\ddot{f}\}_{n}+\{\ddot{f}\}_{n+1}\right) .
\end{aligned}
$$

Since the stiffness matrix $\left[K^{*}(f)_{n+1}\right]$ in $(4.6)$ is non-lincar, and iterative procedure is needed to solve the equation. Using the direct iteration technique, equation (4.6) can be expressed as.

$$
\left[K^{*}(f)_{n+1}^{(k)}\right]\{f\}_{n+1}^{(k+1)}=\left\{F^{*}\right\}_{n+1},
$$

where $k$ is the iteration number. At any fixed time for the $(k+1)^{\text {th }}$ iteration, the stiffness matrix $\left[K^{*}(f)_{n+1}^{(k)}\right]$ is computed using the solution vector from the $k^{\text {th }}$ itcration. The successive solution vector are checked using the following convergence criterion

$$
\left(\sum_{i=1}^{3}\left|f_{i}^{(k)}-f_{i}^{(k+1)}\right|^{2} / \sum_{i=1}^{3}\left|f_{i}^{(k)}\right|^{2}\right)^{1 / 2} \leqslant \varepsilon
$$

where $\varepsilon$ is a given small value. Convergence may be accelerated using a weighted average from the previous iterations according to the equation

$$
\left[K^{*}\left(\alpha\{f\}_{n+1}^{(k-1)}+(1-\alpha)\{f\}_{n+1}^{(k)}\right)\right]\{f\}_{n+1}^{(k+1)}=\left\{F^{*}\right\}_{n+1},
$$

where $0<\alpha<1$. 


\section{NUMERICAL EXAMPLES}

The shallow shell considered here is a spherical panel with in-plane edges $a=$ $b=2 \mathrm{~m}, k_{1}=k_{2}=1 / R$. The shell is simply supported at all its edges. The skin of the shell had 4 plies $[45 /-45 /-45 / 45]$, each ply being $1.5 \mathrm{~mm}$. The typical properties of the fiber-reinforced composite considered in examples refer to the AS4/3501 graphite/epoxy and are

$$
\begin{array}{ll}
E_{1}=144.8 \mathrm{GPa}, & E_{2}=9.67 \mathrm{GPa} \\
G_{12}=G_{13}=4.14 G P a, & G_{23}=3.45 \mathrm{GPa} \\
\nu_{12}=0.3, & \rho=1389.23 \mathrm{~kg} / \mathrm{m}^{3}
\end{array}
$$

where $E_{1}$ is the longitudinal modulus associated with 1-direction, $E_{2}$ is the transverse modulus associated with the 2-direction, $\nu_{12}$ is the major Poisson's ratio, $G_{12}, G_{13}$ and $G_{23}$ are the shear modulii associated with 12,13 and 23 planes respectively. The material of the composite stiffeners is the same as that of the skin. The height of the stiffener is equal to $12 \mathrm{~mm}$, while their width $4 \mathrm{~mm}$. The spacings of longitudinal stiffeners and transversal stiffeners $s_{1}=50 \mathrm{~mm}$, and $s_{2}=50 \mathrm{~mm}$ respectively.

Next, results for the dynamic analysis of laminated stiffened shallow shells are presented. The time step $\Delta t$ is taken as $T / 300$ where $T=2 \pi / 1450$ and $t_{n}=n . \Delta t$ for all the transient problems considered. The applied harmonic uniform load is of the form $q\left(x_{1}, x_{2}, t\right)=p \sin 1450 t$, where the magnitude $p$ may be taken variously, while the first natural frequency of the mentioned reinforced composite shell is $\omega_{0}=$ $1406 s^{-1}$.

Figs. 1a and $1 \mathrm{~b}$ show the linear and non-linear transient responses of unstiffenedand cross- stiffened shallow shell with $R=5 \mathrm{~m}$ respectively under the applied harmonic load with magnitude $p=75.10^{3} \mathrm{~N} / \mathrm{m}^{2}$

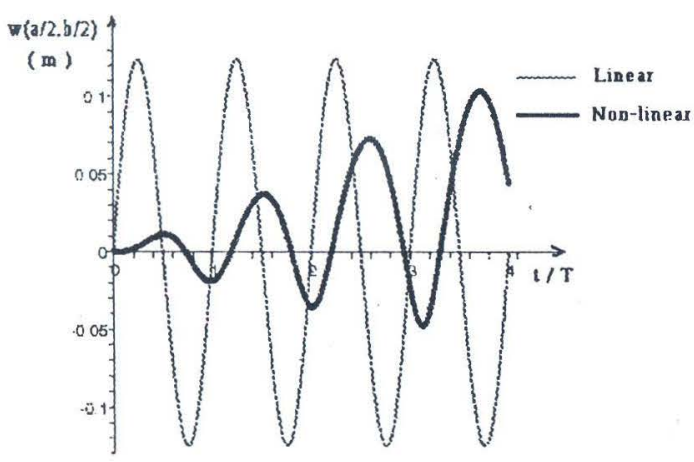

Fig. 1a. Linear and non-linear transient responses of an unstiffened shallow composite shell

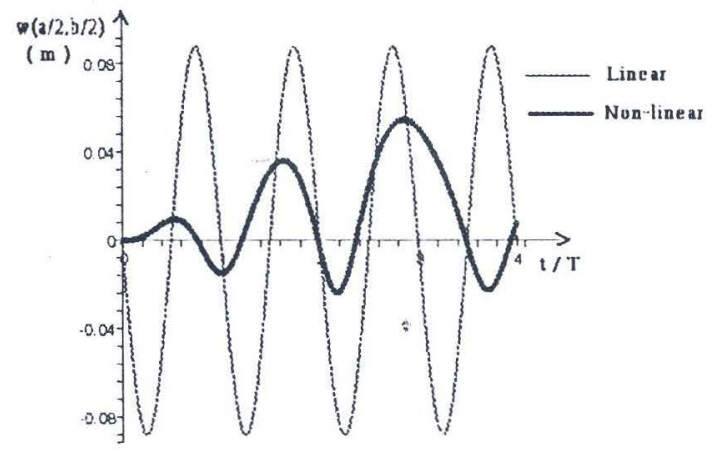

Fig. 1b. Linear and non-linear transient responses of a stiffened shallow composite shell

The effect of geometric non-linearity is apparent from the figure; the linear response is harmonic while the non-linear one is very complicated. It is evident from 
the Fig. 2 that the effect of stiffeners is to decrease the amplitude of the center deflection $w(a / 2, b / 2)$.

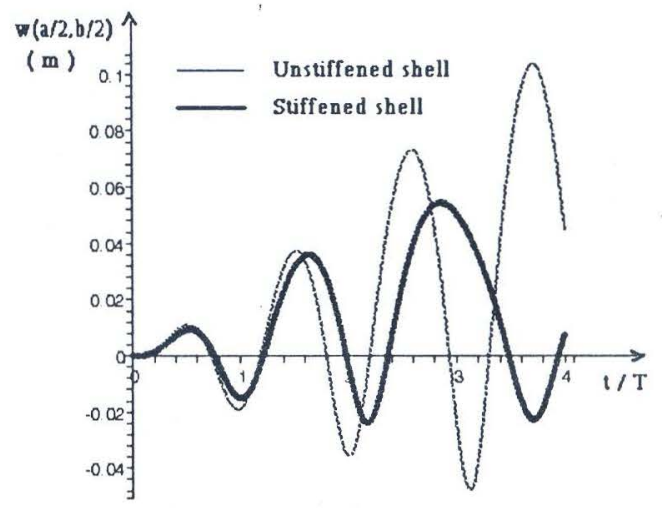

Fig. 2. The effect of stiffeners on amplitude of deflection

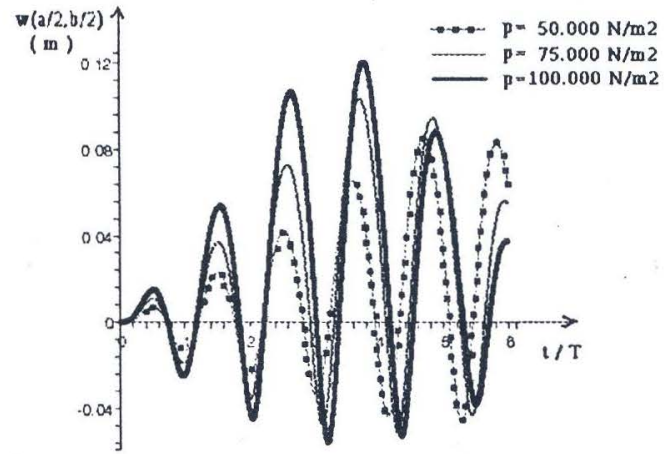

Fig. 3a. Non-linear transient of an unstiffened shell for various applied uniform loads

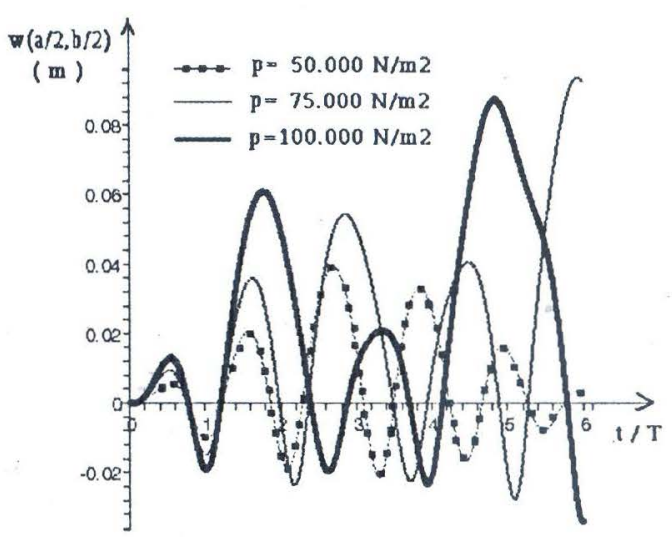

Fig. 3b. Non-linear transient of a stiffened shell for various applied uniform loads

Figs. 3a and 3b show the effect of magnitude of load on the non-linear transient response of an unstiffened shell and a stiffened shell with curvature radius $R=5 \mathrm{~m}$ respectively.

The effect of increasing load on the amplitude of the center deflection is apparent from the figures.

Finally, the effect of shell geometry on the non-linear transient response of an unstiffened shell and a stiffened shell under applied load with $p=75.10^{3} \mathrm{~N} / \mathrm{m}^{2}$ is studied. The results are shown in Figs. $4 \mathrm{a}$ and $4 \mathrm{~b}$. The shell with greater curvature has the lower amplitude of the center deflection. 


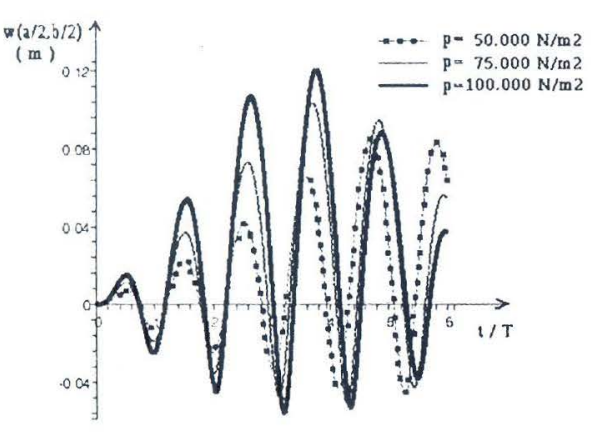

Fig. 4a. Non-linear transient of unstiffened shells for various curvatures

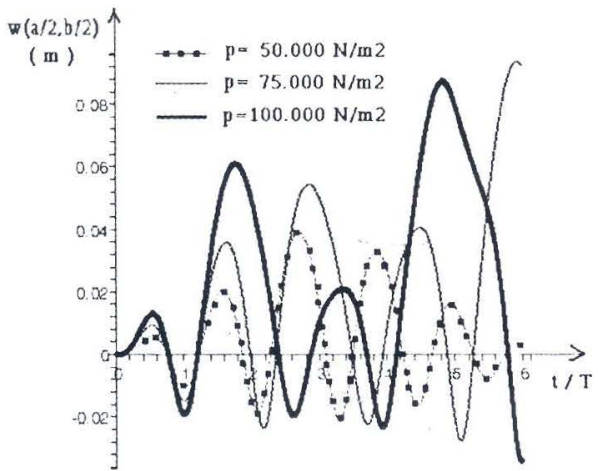

Fig. 4b. Non-linear transient of stiffened shells for various curvatures

\section{CONCLUSION}

The non-linear dynamical behavior of eccentrically reinforced laminated composite doubly curved shallow shells is investigated using the thin shell theory considering the geometrical non-linearity and the Lekhnitsky's smeared stiffeners technique. The resulting non-linear equations are solved by the direct iteration technique in conjunction with the Newmark constant acceleration scheme. Eccentrically stiffened laminated shells with various curvature radius are analyzed and the results are presented for non-linear dynamic responses.

Aknowlegement. This publication is supported by the National Council for Natural Science and the Vietnam National University, Hanoi.

\section{REFERENCES}

1. C. Y. Chia, Non-linear analysis of plates, McGraw-Hill. Inc. 1980.

2. M. Sathyamoorthy, Non-linear vibration analysis of plates: a review and survey of current developments, Applied Mechanics Review 40 (1987) 1553-1561.

3. E. J. Barbero, J. N. Reddy, General two-dimentional theory of laminated cylindrical shells, $A I A A$ Journal 28 (1990) 544-553

4. C. W. Bert, J. N. Reddy, Cylindrical shells of bimodulus composite material, ASCE J. Eng. Mech. 108 (1982) 675-688.

5. C. T. Loy, K. Y. Lam, J. N. Reddy, Vibration of functionally graded cylindrical shells, Int. J. of Mech. Sci. 41 (1999) 309-324.

6. A. A. Khdeir, J. N. Reddy, D. Frederick. A study of bending, vibration and buckling of cross-ply circular cylindrical shells with various shell theories, Int. J. of Eng. Sci. 27 (1989) 1337-1351.

7. A. Nosier, J.N. Reddy. Vibration and stability analyses of cross-ply laminated circular cylindrical shells, J. of Sound and Vibration 157 (1992) 139-159.

8. Tran Ich Thinh, Le Kim Ngoc, Buckling analysis of laminated cylindrical composite shells panel under mechanical and hygrothermal loads, Vienam Journal of Mechanics 27 (2005) 1-12.

9. J. M. Whitney, C. T. Sun. A refined theory for laminated anisotropic cylindrical composite shells, J. Appl. Mech. 41 (1974) 471-466.

10. V. Birman, Theory and comparison of the effect of composite and shape memory alloy stiffeners on stability of composite shells and plates, Int. J. of Mech. Sci. 39 (10) 1139-1149.

11. V. Birman, On the post buckling behavior of reinforced composite shells, J. Ship Res. 34 (1990) 207-211. 
12. A. E. Bogdanovich, Non-linear problems of the dynamic buckling of reinforced laminar cylindrical shells, J. Appl. Mech. 22 (1968) 745-753.

13. R. P. Lei, E. R. Johnson, Z. Gurdal, Buckling of imperfect, anisotropoic, ring-stiffened cylinders under combined loads, AIAA Journal 32 (1994) 1302-1309.

14. M. Savoia, J. N. Reddy, Post buckling behavior of stiffened cross-ply cylindrical shells. J. Appl. Mech. 61 (1994) 998-1000.

15. J. N. Reddy, K. Chandrashekhara, Geometrically nonlinear transient analysis of laminated doubly curved shells, I. J. Nonlinear Mech. 20 (1985) 79.

16. J. N. Reddy, Mechanics of laminated composite plates and shells. Theory. and analysis. $2^{\text {nd }}$ edition, CRC Press, 2004.

17. Dao Iluy Bich, Non-linear analysis of laminated composite doubly curved shallow shells, Vietnam Journal of Mechanics 28 (2006) 43-55.

Received May 21, 2007.

\section{PHÂN TÍCH ĐỘNG LỰC PHI TUYẾN VÒ THOẢI HAI ĐỘ CONG COMPOSITE LỚP CÓ GÂN GIA CƯỜNG}

Bài báo đề cập đến phân tích động lực phi tuyến vỏ thoải hai độ cong compositc lớp có gân gia cường. Phương trình chuyển động của vỏ được thiết lập dựa trên lý thuyết vơ mỏng có tính đến phi tuyến hình học và kỹ thật tính gân gia cường theo Lekhnitsky. Nhờ phương pháp BubnovGalerkin nhận được hệ phương trình giải các phương trình vi phẩn thường phi tuyến. Đáp ứng phi tuyến của vỏ được tính toán nhờ sơ đồ NewMark và thuật toán gàn đúng liên tiếp. Kết quả nhận được cho thấy ành hường của gân và hình học nội tại của vỏ đến đáp ứng động của vò composite lớp có gân đặt lệch tâm. 